
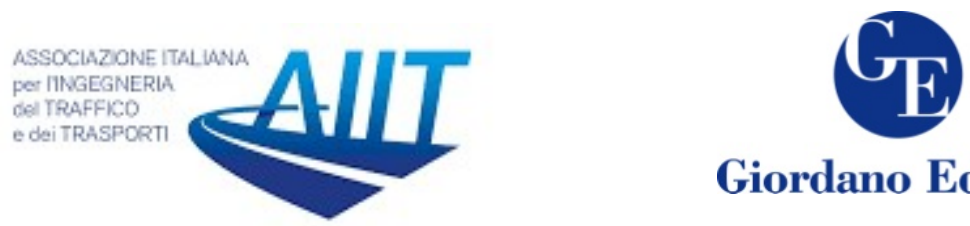

Giordano Editore

\title{
Sharing of trips before electrification of fleet: a cost- effective solution for reducing the environmental impact of urban freight transport in developing countries
}

\author{
Bhavesh Dhonde $^{1 *}$, Chetan R. Patel ${ }^{2}$ \\ ${ }^{1}$ Research Scholar, Department of Civil Engineering, Sardar Vallabhbhai National Institute of \\ Technology, Ichchanath, Surat - 395 007, India. \\ ${ }^{2}$ Assistant Professor, Department of Civil Engineering, Sardar Vallabhbhai National Institute of \\ Technology, Ichchanath, Surat - 395 007, India.
}

\begin{abstract}
Various research efforts are undertaken to reduce the ill-effects of urban freight transport on the city's environment. Replacing conventional freight vehicles with electric commercial vehicles (ECVs) is considered as the most effective solution; however, this transition is facing several technological and infrastructural challenges. In developing countries, where cities are already struggling to manage with their present infrastructure, they would find it even more difficult. This paper highlights the opportunity for sharing of in-use freight vehicles as an immediate solution to reduce vehicular emissions. Case study of Surat city, India is taken to assess the use of small-sized commercial vehicles for urban freight transport. A detailed study has been carried out to determine the extent of under-utilized or unutilized capacities of these vehicles. Reductions in emissions due to the sharing of trips are estimated. Propositions are made to strategize and develop policies that promote sharing of urban freight trips.
\end{abstract}

Keywords: urban freight transport, shared freight trip, city logistics, vehicular emissions.

\section{Introduction}

On one hand urban freight transport (UFT) is inevitable for sustenance and growth of cities as it provides us with several goods and services that we need, while on the other it is one of the major contributors to environmental pollution in our cities as well as for the overall climate change due to the carbon dioxide emissions. Therefore, it is necessary to continuously examine the possibilities for reducing the negative impacts of UFT systems thereby also maintaining its efficiency (Figenbaum, 2018). In India freight transport industry has witnessed two major changes in the last two decades, first is the

\footnotetext{
*Corresponding author: Bhavesh Dhonde (bhaveshdhonde@gmail.com)
} 
downsizing of commercial vehicles owing to various restriction on dimensions of vehicles allowed in cities and narrow streets in some parts of the city, second is the use of diesel instead of petrol as a fuel for small-sized commercial vehicles (with capacity up to 3 tonnes) due to the taxation system and incentives which were applied to fuel types at the national level till the year 2017. In India commercial vehicles are categorized into three segments based on its maximum allowable gross vehicle weight (GVW), heavy commercial vehicles (HCV) having GVW more than 16.2 tonnes, Medium commercial vehicles (MCV) having GVM between 7.5-16.2 tonnes and light commercial vehicles (LCV) having GVW less than 7.5 tonnes. HCVs and MCVs are preferred for long-distance freight transport and LCVs are used for urban and short distance trips (TCI Report, 2015). In all major cities, diesel vehicles especially the older ones (having poor emission regulation) are of critical concern due to the environmental pollution caused by its emissions. In Delhi, diesel vehicles older than 10 years have been banned since 2017. Many cities have identified areas with restricted traffic during peak hours. The government is promoting various benefits for the use of alternate fuel like compressed natural gas $(\mathrm{CNG})$ and electric commercial vehicles (ECVs), which is also aligned with the government's vision to completely shift from petroleum oil-based vehicles to electric vehicles by 2030 .

Electric commercial vehicles have been identified as an eco-friendly and sustainable solution to avoid the emissions generated by urban freight movement. Most of the cities in the European Union have already started to use ECVs for their urban freight trips. Though ECVs are an ideal replacement of conventional vehicles from the environmental benefits point of view, the transition from in use conventional diesel-run vehicles towards ECVs for freight movement would require enough time and resources for a large and developing nation like India. Before this transition is completed, emissions from present urban freight trips also need to be kept in a close check. This paper identifies the possibilities for the sharing of intra-urban freight trips as a measure to reduce the adverse effects of UFT on the city's environment and traffic flows as well. A case study of the Surat city of Gujarat province has been taken up. Surat is a moderately dense city (as compared to the mega-cities like Mumbai and Delhi) with a very fast-growing population due to its industrial development. This study uses an exploratory approach to identify the practical and economic potential for the sharing of urban LCV trips. Traffic studies conducted by Surat Urban Development Authority (SUDA), the city's planning body for assessing urban mobility needs have been referred to in the present study. Several field surveys have also been conducted to understand the supply chain of major commodities being transported in the city. The use and impact of different categories of freight vehicles have been identified.

Surveys have been conducted for different stakeholders at several locations in the city for collecting data on urban freight movement. Average trip length, vehicle type, quantities of goods transported and origin-destination pairs have been estimated based on the data collected. Freight intensive industries are identified and studied in further detail. The textile industry is found to generate the highest number of urban freight trips, almost $40 \%$ of the total internal urban freight trips in the city. Fast-moving consumer goods (FMCG) produces the second-highest number of freight trips (33\%). Phase wise implementation of sharing of urban freight trips is planned and the reduction in noise and air pollution is estimated. Societal benefits and commercial limitations, both are discussed to find a perfect trade-off suitable for different stakeholders involved. 


\section{Theoretical background}

Globally, urban freight traffic accounts for $10 \%$ to $15 \%$ of kilometers travelled and it emits approximately only $6 \%$ of all transport-related greenhouse gases (GHG) emissions, however these emissions entirely in densely populated areas (ALICE, 2014). Though the share of UFT in the overall vehicular emissions is small, it has concentrated effects on limited city spaces where it is generated. Urban freight transport is considered as one of the most complicated systems because of the large number of factors involved, numerous stakeholders, their conflicting priorities, geographical and policy restrictions, sustainability and environmental impacts of moving goods (Holguin-Veras, 2012). These factors make UFT a highly uncertain transport area. The impact of UFT on environmental sustainability is hence high uncertain and needs a close and continuous watch for estimating and predicting its effects. (Nocera et al., 2018). Cities are spaces with the highest degree of human activity, geographic characteristics of the UFT sector like its unevenness, separation, coloniality, and continuity directly affects the emission generated (Schwanen, 2019). Referring to the urban freight sector, the limited amount of official data and statistics is available for vehicles up to 3.5 tonnes loading capacity, which represents a limitation for in-depth studies. Despite growing interest in sustainable transport, issues related to electric LCVs have received limited attention globally (Pelletier et al., 2014).

The majority of studies conducted on sustainable urban transport have focused on passenger transport. However, a well-recognized prerequisite for reaching sustainable urban transport is integrated transport planning including both passenger and freight transport. Accordingly, some big cities, like London and Paris are paying more attention to freight transport as part of their overall transport strategies (Browne et al., 2007). Russo and Comi (2010) classified the effort of UFT studies based on several factors like end-consumer and logistics freight transport, depending upon the stakeholder's involvement like shipper, receivers, carriers. It can also be studied by an individual stakeholder's perspective. Authors have also classified the measures adopted for improving the efficiency of UFT systems into different classes like infrastructural measures, management measures, technological innovation and governance measures (Russo and Comi, 2010). The present effort can be categorized into management measures based on the optimization of existing infrastructure. For urban areas to prosper, transport planning needs to be integrated with land-use planning as well as be included in the strategic planning towards city visions (Banister, 2002 and 2008). Apart from single transport measures, there is also a need for coordination between passenger and freight transport. For UFT planning, there has to be a multistage modeling approach that tries to point out the relations existing among city logistics measures, actors and choice dimensions. It comprises three model subsystems to estimate the quantity $\mathrm{O}-\mathrm{D}$ matrices by transport service type (e.g. retailer on own account or wholesaler on own account or by carrier), the delivery $\mathrm{O}-\mathrm{D}$ matrices by delivery time, and the vehicle $\mathrm{O}-\mathrm{D}$ matrices according to delivery tour departure time and vehicle type. (Nuzzolo and Comi, 2014). A similar analysis of freight trip attraction (FTA) and its relationship with key features using spatial econometric techniques to assess the role of spatial effects among establishments and the urban environment, where the results show that FTA is better modeled as a nonlinear function of employment and other locational variables (Sanchez-Diaz et al., 2016). Bringing urban analysis and spatial studies closer to urban logistics appears to be relevant to tackle last mile issues. A spatial analysis coupled with 
a logistical approach provides a relevant diagnosis for urban logistics practitioners and local authorities, before the settlement of logistics organizations or new regulations that suit cities' characteristics, assets and constraints (Ducret, 2016). Gonzalez -Feliu (2019) carried out a comparison of constant FTG estimations for three different aggregation levels of activity-based categories to derive different functional forms. It is observed that suitable functional form can reduce the need for more disaggregated data, which can reduce the overall cost of collecting data.

Available studies on urban freight transport and the LCV (Enclose, 2014; Feng and Figliozzi, 2012; Quack et al., 2016) provide some insights about the adoption of electric vehicles in European cities. Parameters such as relative price increases of new vehicles, the relative prices of oil and electricity developments in the availability of recharging infrastructure are all relevant both in the private cars and commercial vehicles alike (Rezvani et al., 2015). The uptake of electric LCVs is still limited and only a few operators are replacing their diesel fleets (Figenbaum, 2018). In 2015 just $0.5 \%$ of 1.7 million newly-registered vans in Europe were equipped with plug-in electric technology (EAFO, 2016; ACEA, 2016). The transition from conventionally powered diesel vehicles towards electric vehicles in urban freight transport is not an easy one. Some research papers examine the barriers and opportunities to use electric freight vehicles in city logistics operations (Morganti and Browne, 2018; Mtalaa et al., 2014). Some recent efforts focussing on sustainability goals through the use of EVs enable us to think beyond conventional methods. Generating of electric power using tidal energy and utilizing the same for operating EVs in a port area in Italy is one such example (Croce et al., 2019; Musolino et al., 2019). Sharing of vehicles on the other end is an age-old concept in the field of freight transportation. Long-distance freight transport does share of vehicle payload in all parts of the world. Urban freight transport sharing is also implementing in recent times for delivering goods by private service providers or online megastores like Amazon and eBay. In developing counties urban freight transport is in a poor state of affairs as compared to the already developed countries. Sharing of local urban trips by providing a suitable online platform and reliable infrastructure can provide some relief to the already overburdened transport infrastructure in its cities.

\section{Urban freight transport scenario in Surat}

In the project study of the comprehensive Mobility Plan (CMP) conducted by SUDA, to estimate current employment and goods vehicle movement patterns within the city, various activity surveys have been carried out. These surveys helped in estimating internal-internal goods movement in the study area. There are about 362 thousand nonresidential (NR) properties within the city limits, which are categorized into 102 types of different usages by the Property Tax Department (SUDA). Around 30 different types of usages were identified which have freight transport intensive operations and can be associated with goods movement within the city. A total of about 3069 NR properties were surveyed during the study $(0.85 \%$ sample size $)$. Out of the total surveyed properties, about $865(28 \%)$ properties are associated with goods movement daily. During the surveys, their daily travel pattern of goods movement was captured along with their origin and destination, type of vehicle frequencies, etc. The internal goods movement was observed to be of short distance, higher in number and decentralized in nature. 
These freight-generating activities are concentrated at the places where different stages of the manufacturing process of goods/materials are involved. The map below represents the goods-oriented properties concentration within the city. The Activity Survey data revealed that most of the internal to internal movement happens through the LCVs. The estimated internal-internal vehicle movement is about 270 thousand vehicle trips per day, out of which 261 thousand is by the LCVs and around 9000 trips by heavy trucks i.e. HCVs and MCVs. LCVs are very popular in use due to its smaller dimensions, which makes it easier to manoeuvre in busy streets and congested areas of the city.

Table 1: Urban freight trips (Internal-Internal) per day from major industries in Surat

\begin{tabular}{lcccccc}
\hline $\begin{array}{l}\text { Type of } \\
\text { Industry/ Type } \\
\text { of commercial }\end{array}$ & \multicolumn{2}{c}{ LCVs } & \multicolumn{2}{c}{ MCVs and HCVs } & \multicolumn{2}{c}{$\begin{array}{c}\text { Total freight trips from } \\
\text { particular industry }\end{array}$} \\
\cline { 2 - 7 } vehicle & $\begin{array}{c}\text { Number of } \\
\text { trips }\end{array}$ & $\begin{array}{c}\text { Percentage of } \\
\text { total trips }\end{array}$ & $\begin{array}{c}\text { Number of } \\
\text { trips }\end{array}$ & $\begin{array}{c}\text { Percentage of } \\
\text { total trips }\end{array}$ & $\begin{array}{c}\text { Number of } \\
\text { trips }\end{array}$ & $\begin{array}{c}\text { Percentage of } \\
\text { total trips }\end{array}$ \\
\hline Textiles & 105108 & $40 \%$ & 3487 & $43 \%$ & 108595 & $40 \%$ \\
FMCG & 87375 & $33 \%$ & 270 & $3 \%$ & 87645 & $33 \%$ \\
$\begin{array}{l}\text { Chemicals and } \\
\text { oils }\end{array}$ & 10847 & $4 \%$ & 3103 & $39 \%$ & 13950 & $5 \%$ \\
$\begin{array}{l}\text { Manufacturing } \\
\text { machines and }\end{array}$ & 25662 & $10 \%$ & 1107 & $14 \%$ & 26769 & $10 \%$ \\
$\begin{array}{l}\text { equipment } \\
\begin{array}{l}\text { Other } \\
\text { industries }\end{array}\end{array}$ & 32089 & $12 \%$ & 74 & $1 \%$ & 32163 & $12 \%$ \\
Total trips & 261081 & $100 \%$ & 8041 & $100 \%$ & 269122 & $100 \%$ \\
\hline
\end{tabular}

Source: Comprehensive Mobility Plan- 2046 (SUDA), 2018.

Out of total LCV movements within the city, major contributors are textiles and FMCG, which accounts for $40 \%$ and $33 \%$ of the total LCV trips respectively. HCV and MCV trips consist of only $3 \%$ of the entire urban freight trips, considering only internalinternal movement. These trips are also conducted only during off-peak timings due to the restrictions imposed by traffic police for heavy vehicles during day time. As textiles contribute around $40 \%$ in overall goods vehicle trips, it becomes essential to understand the supply chain of textiles in detail. Also textile has some inherent benefits not available to an industry like FMCG or chemicals. Textile goods are more durable than FMCG and do not need any special care while handling like chemical goods. The spread of the textile industry in the city is quite measurable and relatively constant, which makes tracking of textile freight trips easier as compared to FMCG trips. This made textile goods transport a natural choice for making in-depth analysis for achieving the study objective. However, FMCG being the second-highest trip generating industry also needs to be studied, which could be taken up as a further continuation of the study.

\section{Estimation of trip length and vehicle loads}

For estimation of the freight trip lengths and a vehicle load factor of LCV trips, interviews were conducted for transport providers and drivers of LCVs. From interviews of major freight transport service providers in the city, it was observed prima facie that LCV operations are dominated by individual LCV owners, providing demandbased services and the concept of carrier service (transport service provider) is restricted to only $\mathrm{HCV}$ and MCV trips, that too only for long-distance hauls or regional trips. Also 
for the transport of textile-related goods within the city, the majority of the trips are made using hired vehicles. Only a very small percent of the overall textile industry is having its vehicles for the transport of goods. Hired LCVs are easily available in almost all parts of the city where textile-related establishments have been set up. To understand the origin-destination pattern, freight loading factor and times spent in loading and unloading of consignments, drivers' survey of commercial vehicles and was carried out in the major commercial areas of the city. For the textile industry, the ring road market is acting as a key distribution center for raw, semi-finished and finished goods. Drivers' survey was conducted for two consecutive weeks as these commercial areas are very congested and it was quite difficult to find time from respondents. Considering the ring road market as the origin point, destination pattern for the majority of the trips and average trip lengths for these trips obtained from the survey is shown in figure 1.

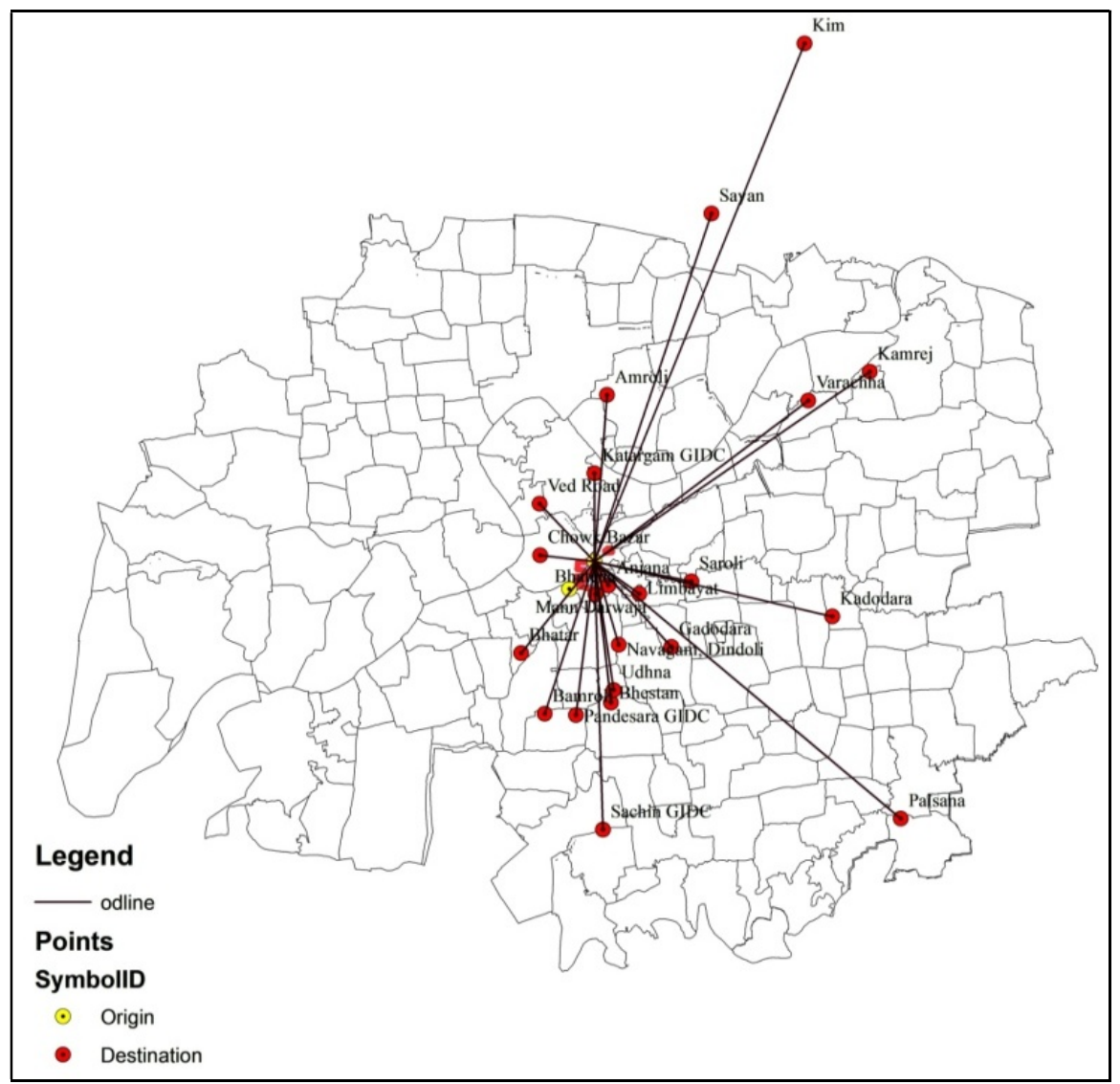

Figure 1. O-D map of LCV trips for textile goods

From the carrier's survey, the origin-destination of 1137 LCV trips was worked out. Table 2 shows the results obtained from the origin-destination of trips. Origindestination showed there are two types of major trips carried through LCVs. One is within the commercial area (local due to trading of various textile goods) and another is between the production units and commercial area or vice versa. 
Table 2. Internal LCV trips from distribution centers to various textile clusters

\begin{tabular}{|c|c|c|c|}
\hline $\begin{array}{l}\text { Destination of LCV trips originating } \\
\text { at ring road commercial area } \\
\text { (distribution center) }\end{array}$ & $\begin{array}{c}\text { Number of } \\
\text { trips }\end{array}$ & $\begin{array}{c}\text { Distance to } \\
\text { production clusters } \\
(\mathrm{km})\end{array}$ & $\begin{array}{l}\text { Percentage of } \\
\text { the total trips }\end{array}$ \\
\hline Local trips with commercial area & 246 & upto $1 \mathrm{~km}$ & 21.6 \\
\hline Varacha & 139 & 14.2 & 12.2 \\
\hline Pandesara GIDC & 130 & 9 & 11.4 \\
\hline Kadodara & 83 & 11.1 & 7.3 \\
\hline Sachin GIDC & 73 & 14.9 & 6.4 \\
\hline Palsana & 58 & 21.8 & 5.1 \\
\hline Udhna & 46 & 7.6 & 4.1 \\
\hline Saroli & 44 & 4.8 & 3.9 \\
\hline Bhatar & 41 & 6.8 & 3.6 \\
\hline Kamrej & 34 & 18.2 & 3.0 \\
\hline Katargam GIDC & 28 & 5.7 & 2.5 \\
\hline Ved road & 24 & 5.1 & 2.1 \\
\hline Anjana & 23 & 2.6 & 2.0 \\
\hline Dindoli & 20 & 4.9 & 1.8 \\
\hline Gadodara & 16 & 6.7 & 1.4 \\
\hline Sayan & 16 & 21 & 1.4 \\
\hline Bhatena & 13 & 2.6 & 1.1 \\
\hline Limbayat & 12 & 3.3 & 1.1 \\
\hline Bamroli & 10 & 8.9 & 0.9 \\
\hline Bhestan & 10 & 6.9 & 0.9 \\
\hline Kim & 10 & 34.4 & 0.9 \\
\hline Amroli & 6 & 9.3 & 0.5 \\
\hline Chowk bazar & 6 & 2.7 & 0.5 \\
\hline Others & 49 & 6.2 & 4.3 \\
\hline $\begin{array}{l}\text { Total number of } \\
\text { LCV trips }\end{array}$ & 1137 & $\begin{array}{c}\text { Average trip length } \\
11.17 \mathrm{kms}\end{array}$ & $100 \%$ \\
\hline
\end{tabular}

The number of trips at a particular destination and percentage distribution considering the total origin-destination pairs is also shown in table 2. The other origin/destination includes area such as Kapodara, Karanj, Kosad, Olpad, Parvat-patiya which have very less number of trips. as compared to the other areas mentioned in table 2. Other than local trips in the commercial area, it is observed that the highest number of trips is attracted by Varachha (12.2\%) followed by Pandesara GIDC(11.4). Whereas maximum trip length is for Kim $(34.4 \mathrm{~km})$ followed by Palsana $(21.8 \mathrm{~km})$. The average trip length from this O-D study observed was $11.17 \mathrm{~km}$. During the drivers' survey information regarding the payload capacity and capacity utilization as well as the percentage of loaded/empty trips was also determined. Both these factors are important for finding the actual unutilized capacity of these LCV trips. The unutilized capacity of LCV vehicles can be optimized by sharing of freight trips. This would benefit the service provider in terms of more earning per unit kilometer traveled as well as shippers in the terms of more availability of LCV and lower transportation cost as compared to the individual vehicle hired. Figure 2 shows some of the pictures taken at the study area which indicates empty trips and partly loaded trips by freight vehicles. Empty and partly loaded LCVs are indicated by yellow circles in the pictures. 

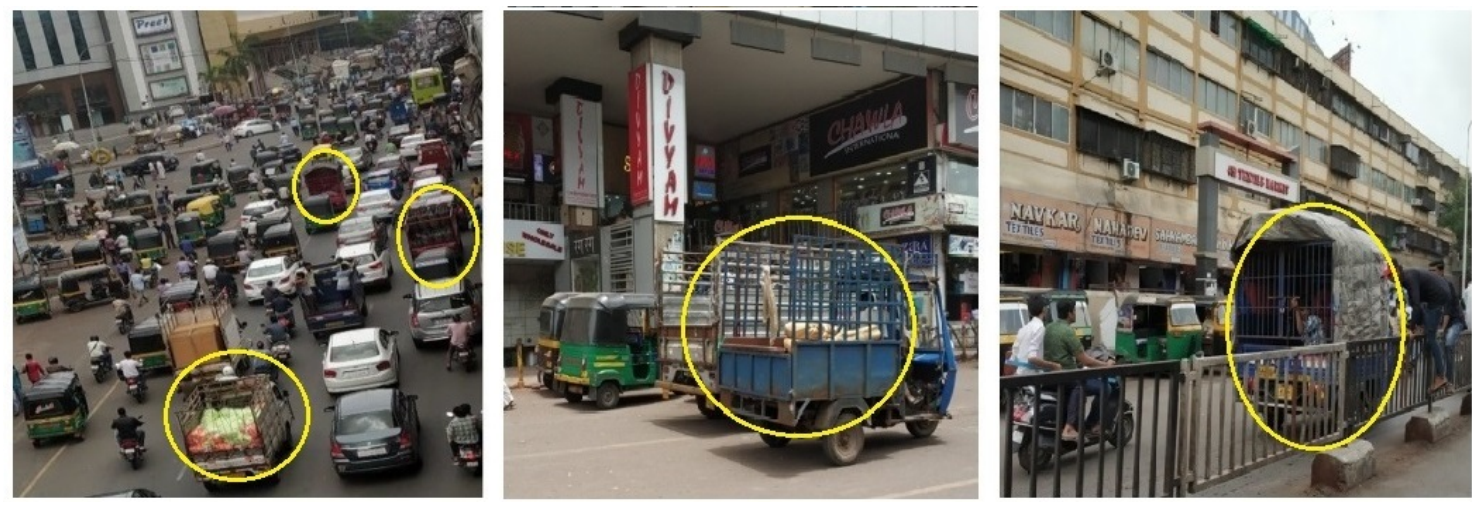

Figure 2. Images showing LCVs carrying part load and empty trips in study area

\subsection{Payload utilization}

A variety of commercial vehicles from different manufacturers having different payload capacities are available under the category on LCV in the Indian market. Small vehicles with a payload of only $500 \mathrm{~kg}$ to bigger size vehicles with payload upto 4000 kgs are used in the textile market depending upon the requirement, suitability and financial condition of the owner of the vehicle. From the data collected during the survey, it is found that $94 \%$ of the total vehicles were on 12 popular brands. Details of their payload and capacity utilization are given in table 3.

Table 3. Different types of LCVs used in textile industry Surat and their payload utilization

\begin{tabular}{lcccc}
\hline Model/make of LCV & $\begin{array}{c}\text { Payload } \\
\text { Capacity }\end{array}$ & $\begin{array}{c}\text { Share of total } \\
\text { sample (\%) }\end{array}$ & $\begin{array}{c}\text { Average loading } \\
\text { capacity used }\end{array}$ & $\begin{array}{c}\text { Percentage of } \\
\text { payload utilization }\end{array}$ \\
\hline Bajaj Maxima & 470 & 4 & 300 & 64 \\
Piaggio Ape & 560 & 9 & 360 & 64 \\
Atul Shakti & 585 & 18 & 340 & 58 \\
Tata Ace & 605 & 17 & 490 & 81 \\
Piaggio porter & 1000 & 3 & 670 & 67 \\
Tata Mega & 1030 & 7 & 750 & 73 \\
Mahindra Bolero & 1200 & 9 & 970 & 81 \\
Ashok leyland Dost & 1475 & 6 & 1200 & 81 \\
Force Shakti man & 1700 & 4 & 1250 & 74 \\
Eicher Pro 1049 & 2679 & 8 & 2000 & 75 \\
SML Isuzu5252 & 2890 & 5 & 2400 & 83 \\
Tata 407 & 3830 & 4 & 3150 & 82 \\
Others & 1250 & 6 & 800 & 64 \\
\hline \multicolumn{5}{c}{ Total (\%) } \\
\hline \multicolumn{5}{c}{ Average capacity } \\
\hline
\end{tabular}

On an average $73 \%$ capacity utilization is taking place as per the data obtained from 1137 drivers. It is also observed that for the LCVs with payload capacity more than $1500 \mathrm{kgs}$, the payload utilization is higher (75\%-83\%), while for vehicles with low capacity of payload (upto $1000 \mathrm{kgs})$ the payload utilization in lower (64\%-73\%), except for Tata Ace, which has an average payload utilization of $81 \%$. From this analysis, it can be derived that smaller vehicles have more tendency of under loading as compared to bigger vehicles in the LCV segment also. Also, $67 \%(2 / 3 \mathrm{rd})$ of the vehicles are found 
to have a loading capacity of around 1 tonne only. With $27 \%$ of the total loading capacity going idle, there is surely some scope for sharing of freight trips in loaded trips condition also. Drivers' survey reveals that though the distance covered in these freight trips is comparatively lesser, the volume of these trips can make the UFT in the textile industry complex.

\subsection{Percentage of loaded/empty trips}

LCVs are very easily available and convenient mode for goods transport, especially for the consignment of small sizes. A large number of LCV operates as a hire vehicle in the city, which leads to easy availability and affordable prices for its services. This has also lead to a large number of trips that are loaded for only one-way movement along its trip. The return trip of the LCV trips is found to be empty in many cases. The same has been recorded during the drivers' survey and observed during field visits for data collection. For the collected samples a 422 out of 1137 trips were found to be empty. Figure 3 below indicates the percentage of LCV trips in Surat based on the survey conducted.

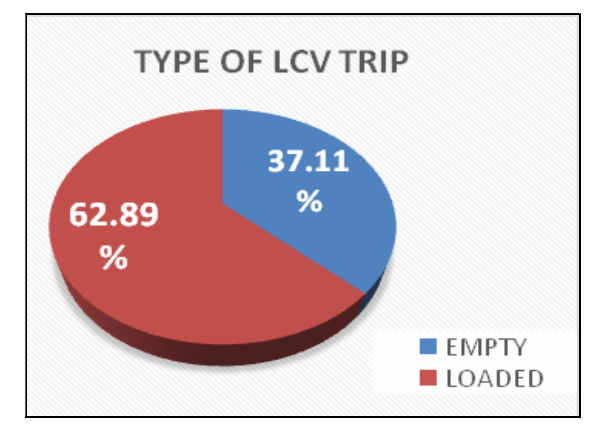

Figure 3. Distribution of freight trip w.r.t it loading condition

From the above analysis, it is derived that freight trips generated in the textile industry are underutilizing its payload capacities by around $27 \%$ and around $37 \%$ of the total trips generated are empty, which indicates that there is a lot of scope for efficient resource utilization in UFT industry in the city. The textile industry generates $40 \%$ of the total LCV trips in the city (refer table 1), in the next section the amount of freight trips that can be shared is estimated based on the results of the drivers' survey conducted and the results of establishments surveys of non-residential activities conducted by SUDA in 2018.

\section{Estimation of shared urban freight trips}

Freight trips generated in the textile industry can be further divided into several categories based on the trip purpose. The textile manufacturing process consists of 5-6 different phases of production (weaving, dyeing, printing, embroidery, lacework and jari work) and the intracity movement of freight occurs at every phase of production, which leads to a very complex supply chain of goods in the textile industry. However, this complex supply chain is beneficial implementing the concept of shared freight trips. For a simple supply chain process having linear flow, it would have been difficult to use the empty vehicle or underutilized payloads due to the unidirectional flow of materials. Numerous back and forth movement due to the transfer of goods from one unit to 
another provides scope for sharing of UFT for the textile industry. Taking into to account entire unused payload capacity and empty LCV trips, the total amount of trips available for sharing can be estimated using the following function.

$F t_{\text {shared }}=f\left\{a^{*} L_{f t,}, b^{*} E_{f t,} S F_{i j}, T L_{i j}, A_{i j}, U F\right\}$

Where,
$F T_{\text {shared }}:$
is the shared freight trips in vehicle kilometer travel (VKT)
a :
is the percentage of unutilized capacity of LCV trips
$L_{f t} \quad: \quad$ is the number of loaded freight trips
$b \quad: \quad$ is the percentage of emply LCV trips
$E_{f t} \quad: \quad$ is the number of empty freight trips
$S F_{i j}: \quad$ is the sharing factor for freight trips between origin $\mathrm{i}$ and destination $\mathrm{j}$
$T L_{i j} \quad: \quad$ is the trip length or distance between location $\mathrm{i}$ and $\mathrm{j}$
$A_{i j} \quad: \quad$ is the ease of availability of hired LCV along the route from $\mathrm{i}$ to $\mathrm{j}$
$U F \quad$ : $\quad$ is the urgency factor for delivery of goods which depends on the shipper and receivers business requirement

It is not practically possible to force the implementation of sharing of urban freight trips and hence sharing of freight trips can only be developed by providing the required platform and infrastructure which can make sharing of freight trips a reliable and efficient option as compared to the present UFT practices. Also for promoting the sharing of freight trips among various stakeholders in the business, it is necessary to incentivize shared freight trips. This process of increasing awareness is a gradual one and hence implementation of sharing concepts also needs to be put forward gradually in a phased manner. Figure 4 shows the stage-wise implementation of the sharing of freight trips and proportional reduction in the overall VKT due to the textile urban freight movements. For analysis purposes, the sensitivity to incentive schemes and urgency factors of shippers and receivers are not considered at this point, as both these factors are subjective and its assessment is only possible after the implementation of the shared UFT concept. Also, trip lengths are assumed to be uniform.

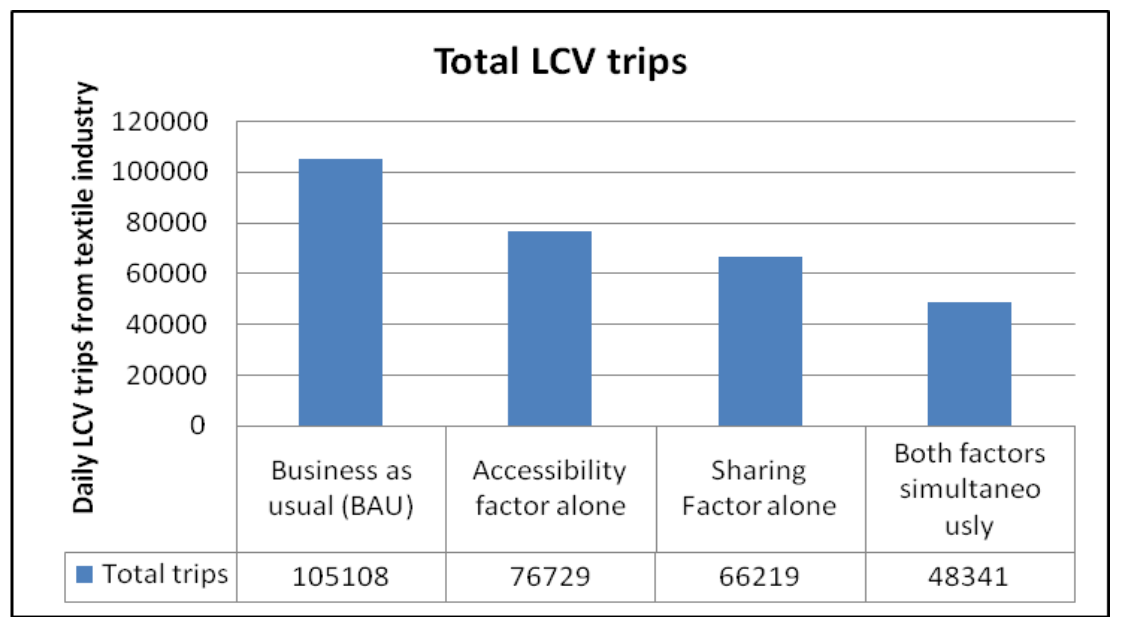

Figure 4. Potential for sharing of LCV trips from textile industry 
It can be observed from figure 4 that four different scenarios are considered for the implementation of the sharing of urban freight trips. For business as usual (BAU) scenario around 100 thousand LCV trips per day are generated by the textile industry. In scenario 2, where the accessibility factor is considered refers to a condition where all the unutilized payload capacities of LCV trips are used up to its full capacity. This can be possible if some shippers share the same freight vehicle for the transport of their goods. Here it is assumed that the accessibility of enroute textile clusters always fills up the entire unused payload. Considering the BAU trip requirement, the total number of trips are bound to reduce when the unutilized payload capacities are used up.

In the third case, it is considered that all the empty trips made by LCV for textile freight are eliminated by sharing the same freight vehicle by other shippers in the production unit or commercial area. In this condition, it is assumed that all the production clusters or commercial areas are in constant need of LCV service and hence any trip made to that area would be refilled by the goods from that area, instead of going empty (as in the present scenario). In the last case benefits of both the above cases are considered simultaneously, which has led to a considerable reduction in the overall LCV trips required to cater to the needs of the textile industry.

\section{Emission reduction}

Emissions from the transport sector depend mainly on the type of transport and fuel apart from the type of combustion engine, emission mitigation techniques, maintenance procedures, and vehicle age. (Ramachandra and Shwetmala, 2009) The major pollutant emitted from transport are Carbon dioxide (CO2), Methane (CH4), Carbon monoxide (CO), Nitrogen oxides (NOx), Nitrous oxide (N2O), Sulphur dioxide (SO2), Nonmethane volatile organic compounds (NMVOC), Particulate matter (PM) and Hydrocarbon (HC). Diesel is used in public passenger and cargo vehicles, while private two-wheelers, light motor vehicles (passenger), car and jeeps use gasoline. As per the prevailing norms (Bharat Stage IV), emission standards for light diesel vehicles which are predominantly used for goods transport in urban areas is shown in table 4.

Table 4: Emission Standards for Light-Duty Diesel Vehicles $(\mathrm{g} / \mathrm{km})$

\begin{tabular}{ccccccc}
\hline Year & Reference & $C O$ & $H C$ & $H C+N O_{x}$ & $N O_{x}$ & $P M$ \\
\hline 1992 & - & $17.3-32.6$ & $2.7-3.7$ & - & - & - \\
1996 & - & $5.0-9.0$ & - & $2.0-4.0$ & - & - \\
2000 & Euro 1 or BS I & $2.72-6.90$ & - & $0.97-1.70$ & $0.14-0.25$ & - \\
2005 & Euro 2 or BS II & $1.0-1.5$ & - & $0.7-1.2$ & $0.08-0.17$ & - \\
& & 0.64 & & 0.56 & 0.5 & 0.05 \\
2010 & \multirow{2}{*}{ Euro 3 or BS III } & 0.8 & - & 0.72 & 0.65 & 0.07 \\
& & 0.95 & & 0.86 & 0.78 & 0.1 \\
& & 0.5 & & 0.3 & 0.25 & 0.03 \\
2017 & \multirow{2}{*}{ Euro 4 or BS IV } & 0.63 & - & 0.39 & 0.33 & 0.04 \\
& & 0.74 & & 0.46 & 0.39 & 0.06 \\
\hline
\end{tabular}

Source: Indian Emission Regulation, ARAI, GOI

Emission factors of road transport, based on the type of vehicle compiled from various literature including regulatory agencies (Mittal and Sharma, 2003; EEA, 2001; 
CPCB, 2007) are listed in Table 3. It is assumed that diesel is used as fuel in buses, omnibuses, taxi, trucks, lorries, light motor vehicles (goods), trailers and tractors, while two-wheelers, light motor vehicles (passenger), car and jeeps use gasoline. Most of the buses and omnibuses and 5\% of total cars and jeeps also use Compressed Natural Gas. $\mathrm{CO}, \mathrm{HC}, \mathrm{NOx}$ and PM emissions from CNG based buses were 1.77, 0.88, 2.81 and $0.032 \mathrm{~g} / \mathrm{km}$ and for cars and jeeps were $0.78,1.55,0.92$ and $0.02 \mathrm{~g} / \mathrm{km}$, respectively (CPCB, 2007). The emission coefficients and net calorific values of light diesel oil which is commonly used as fuel for the light commercial vehicles are CO2 3.18 ton/ton, NO2 $800 \mathrm{~kg} /$ TJ and net calorific value of $43.33 \mathrm{TJ} / 103$ ton. During the drivers' survey, details of the vehicles used were also recorded. From the data it is observed that not all the LCVs used in the city are having the latest emission norms i.e. Bharat Stage IV (BS-IV), on the contrary majority of the LCVs are of the make of previous emission norms. Figure 5 shows the percentage of share of vehicles based on the emission norms.

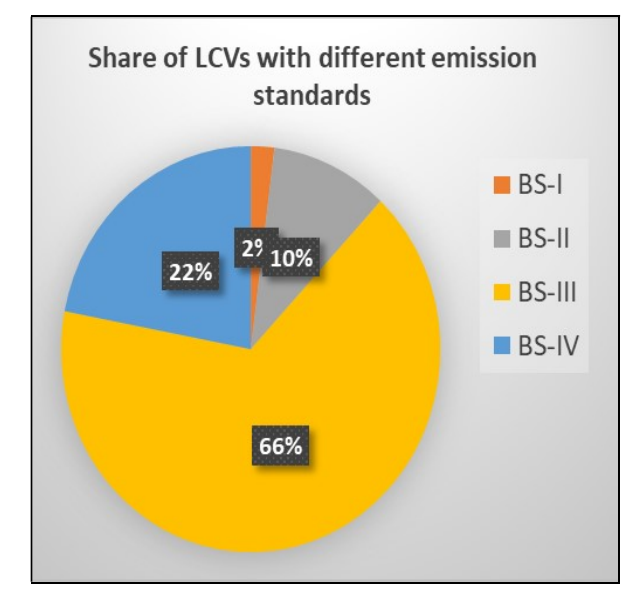

Figure 5: Percentage distribution based emission standards of LCVs

While analyzing the emission generated by the textile industry freight movement the above-mentioned share of different category of freight vehicles or status quo has been considered for BAU scenario as the emissions standards for the different norms of Bharat Stage I, II, III, and IV are quite different from each other (refer table 2). Emissions have been calculated considering the number of freight trips for the textile industry taken from the CMP report and average trip length determined by the drivers' survey.

Emission generated from the urban freight trips of the textile industry is given in figure 6. The total LCV trips are considered for four different scenarios which are discussed in the section above. The percentage share of vehicles with different emission norms is kept as it is for all the remaining three scenarios.

Scenario 1 refers to the complete utilization of the payload of LCV trips. Here the part-load trips made by LCVs are avoided and full capacity loading is completed for every trip made. Here empty trips made by LCVs in one the trip direction is not considered.

Scenario 2 refers to the removal of all empty trips by sharing of freight trips. Here empty trips of LCVs are avoided by proper trip planning and merging two or more partload trips into one. Both to and fro trips of LCVs needs to be loaded trips only. Here part-loading of freight trips is not considered 
Scenario 3 refers to both removal of the unutilized payload as well as the removal of empty freight trips by sharing of freight trips. Both of the above efforts i.e. preferring full load capacity and avoiding empty trips measures are simultaneously considered in this scenario.

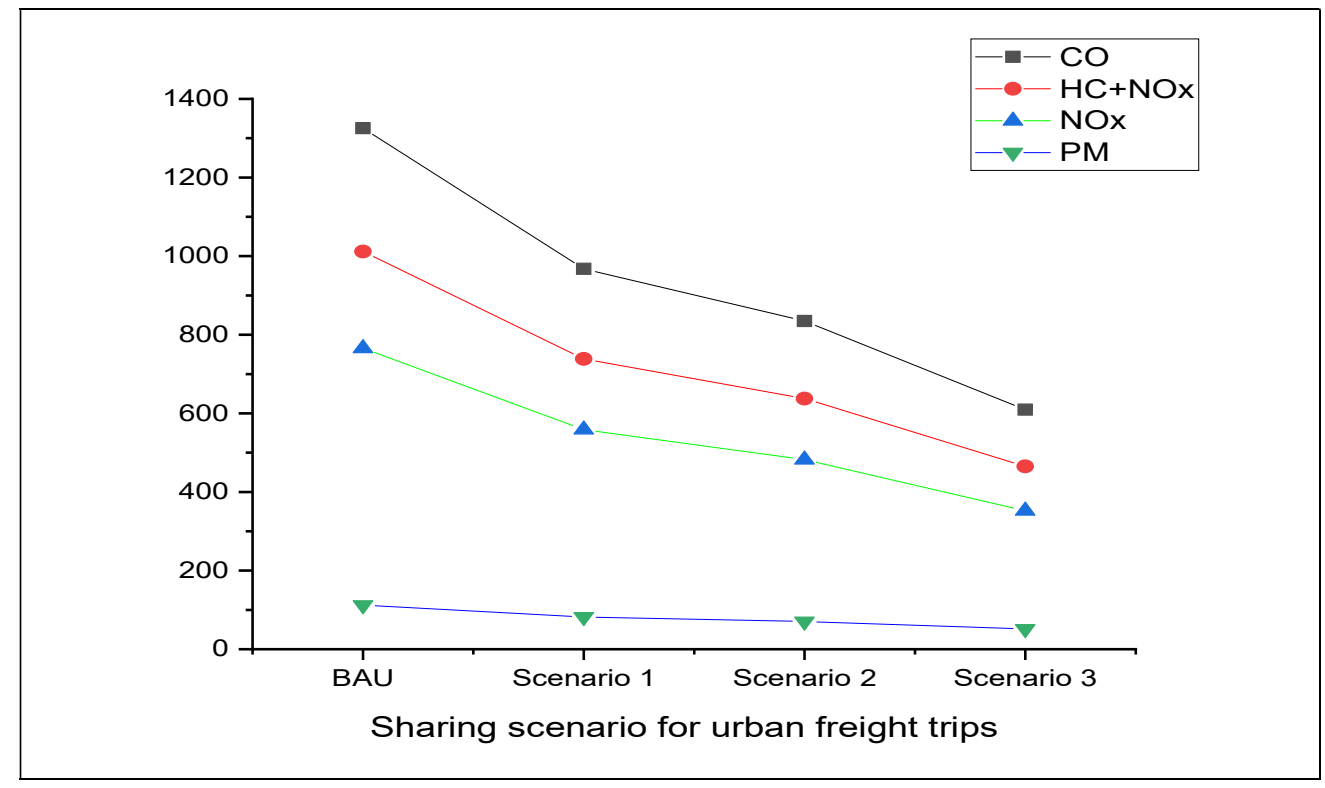

Figure 6. Emissions from urban freight trips and different sharing scenarios

From the graph, it can be inferred that there is a considerable reduction in all the harmful emission causing agents. With the gradual implementation of the sharing of LCV freight trips, emission gets reduced for each scenario. Scenario III (which suggests complete utilization of unused resources can lead upto a $54 \%$ reduction in harmful emissions from the textile freight trips.

\section{Conclusion and suggestions}

The textile industry in the city has the potential to reduce upto $50 \%$ of the total urban freight trips. Due to practical consideration and sprawl of industry in the city, $100 \%$ utilization of resources for sharing might not be possible. Sharing can be introduced in a phased manner to reduce the risk of failure. Different stages of production in the supply chain process can be approached individually for the implementation of shared trips. Reduction in the emission calculated in the section above is direct, which is calculated only for the reduction in the vehicle kilometers traveled. However, the actual emission reduction is bound to be higher than that value because by an overall reduction in the number of freight vehicles on the city roads would lead to reduced congestion in the major commercial area of the city, thereby keep the traffic flow efficient and reducing the emissions caused by congestion and traffic jams. Sharing of freight vehicles for local trips in the textile industry can have multiple benefits to all the stakeholders of the industry as well as for the other commuters of the city. Successful implementation of this concept in the textile industry can open doors for other industries in the city with a high amount of intra-city freight movement.

In the above section benefits from utilizing the unused capacity and avoiding empty freight, trips have been discussed. But actualization of these benefits would occur only 
on the sharing of freight trips by thousands of LCV service providers and seekers. If shared transportation reduces the speed of their transaction in increasing the delivery times, they might let go of the benefits that would arise from shared freight transport. Local government can play a very vital role in promoting the sharing of freight trips by incentivizing sharing and penalizing empty trips during peak hours for congested commercial spaces. Also, the policy framework should be able to develop a positive opinion among the stakeholders for the sharing of urban freight trips.

With the advent of electric LCV, conventional diesel-powered LCVs should get obsolete and go out of the system. Sharing of LCV trips can complement the use of eLCVs also as electrification of vehicles would make our cities cleaner, but sharing of trips can provide us with the additional benefit of decongesting traffic infrastructure. With some extra resources on developing an online platform for sharing of freight trips and policy modifications, sharing of freight trips can provide a sustainable solution to our urban freight transport needs.

\section{References}

ACEA (European Automobile Manufacturer's Association), (2016) "New Commercial Vehicle Registrations in the European Union in 2015".

Alliance for Logistics Innovation through Collaboration in Europe (ALICE) / ERTRAC, (2014), Urban mobility WG - Urban freight research roadmap.

Aggoune-Mtalaa, W., Habbas, Z., Ait Ouahmed, A., Khadraoui, D. (2015) "Solving new urban freight distribution problems involving modular electric vehicles", IET Intelligent Transport Systems, 9(6), pp. 654-661.

Banister, D. (2002). Transport Planning. Taylor and Francis, London.

Banister, D. (2008). "The sustainable mobility paradigm". Transport Policy, 15, 73-80.

Browne, M., Allen, J., Attlassy, M. (2007). "Comparing freight transport strategies and measures in London and Paris". International Journal of Logistics: Research \& Applications, 10, 205-219.

CPCB, (2007) "Transport Fuel Quality for the Year 2005". Central Pollution Control Board, Government of India, New Delhi.

Croce, A.I., Musolino, G., Rindone, C., Vitetta, A. (2019). "Sustainable mobility and energy resources: A quantitative assessment of transport services with electrical vehicles". Renewable and Sustainable Energy Reviews, 113, 109236.

Ducret, R., Lemarié, B., Roset, A. (2016). "Cluster analysis and spatial modeling for urban freight. Identifying homogeneous urban zones based on urban form and logistics characteristics", Transportation Research Procedia, 12, 301-313

EAFO (European Alternative Fuel Observatory) (2016) "Battery-electric vehicle statistics in 2015", Online Dataset. Retrieved 10th October 2018. http://www.eafo.eu/vehiclestatistics/n1.

EEA, (2001) "Joint EMEP/CORINAIR Atmospheric Emission Inventory Guidebook", third edition. European Environment Agency, Copenhagen.

ENCLOSE (Energy Efficiency in City Logistics for Small and Mid-Sized European Historic Towns), (2014) "Electric Fleets in Urban Logistics Report", AustriaTech.

Feng, W., Figliozzi, M. (2012) "Conventional vs electric commercial vehicle fleets: a case study of economic and technological factors affecting the competitiveness of electric commercial vehicles in the USA", Procedia - Social and Behavioural Sciences, 39, pp. 702-711. 
Figenbaum, E. (2017) "Perspectives on Norway's supercharged electric vehicle policy", Environmental Innovation and Societal Transition, 25, pp. 14-34.

Figenbaum, Erik. (2018) "Can battery electric light commercial vehicles work for craftsmen and service enterprises?", Energy Policy, 120, pp. 58-72.

Gonzalez-Feliu, J., Sanchez-Diaz, I. (2019). "The influence of aggregation level and category construction on estimation quality for freight trip generation models". Transportation Research Part E, 121, pp. 134-148.

Holguín-Veras, J., Miguel, J., Sanchez-Diaz, I., Wojtowicz, J., Shama, C., Herbert, L., Lawson, C., Powers, E. L., Tavasszy, L. (2012). "Freight Trip Generation and Land Use", NCFRP, National Academies Press, Washington, USA. doi: 10.17226/23437.

Mittal, M.L., Sharma, C. (2003) "Anthropogenic Emissions from Energy Activities in India: Generation and Source Characterization (Part II: Emissions from Vehicular Transport in India)".

Morganti, E. and Browne, M. (2018) "Technical and operational obstacles to the adoption of electric vans in France and the UK: An operator perspective", Transport Policy, 63, pp. 90-97.

Musolino, G., Rindone, C., Vitetta, A. (2019) "Passengers and freight mobility with electric vehicles: A methodology to plan green transport and logistic services near port areas", Transport Research Procedia, 37, pp. 393 - 400.

Nocera, S., Irranca Galati, O., Cavallaro, F. (2018) "On the Uncertainty in the Economic Evaluation of Carbon Emissions from Transport". Journal of Transport Economics and Policy, 52-1, pp. 68-94,

Nuzzolo, A., Comi, A. (2014). "Urban freight demand forecasting: a mixed quantity/delivery/vehicle-based model". Transportation Research Part E, 65, 84-98.

Pelletier, S., Jabali, O., Laport, G. (2014) "Goods distribution with electric vehicles: review and research perspectives", Transportation Science, 50 (1), pp. 3-22.

Quack, H., Nesterova, N., von Rooijen, T. (2016) "Possibilities and barriers for using electric-powered vehicles in city logistics", Transportation Research Procedia, 12, pp. 157-169.

Ramachandra, T.V., Shwetmala, (2009) "Emissions from India's transport sector: State wise synthesis", Atmospheric Environment, 43 (34), pp. 5510-17

Rezvani, Z., Jansson, J., Jan Bodin, J. (2015) "Advances in consumer electric vehicle adoption research: a review and research agenda", Transportation Research Part D, 34 (1), pp. 122-136.

Russo, F. and Comi, A. (2010) "A classification of city logistics measures and connected impacts". Procedia - Social and Behavioral Sciences, 2 (3), pp. 6355-6365

Sánchez-Díaz, I., Holguín-Veras, J., Wang, X. (2016) “An exploratory analysis of spatial effects on freight trip attraction". Transportation, 43 (1), 177-196.

Schwanen T. (2019) "Transport geography, climate change and space: opportunity for new thinking". Journal of Transport Geography, 81, 102530.

TCI-IIM (2015) "Operational efficiency of freight transportation by road in India", Third Edition of TCI-IIM Calcutta Joint Study Report. Calcutta, India. 